\title{
Google: The World's First Information Utility?
}

\author{
The idea of information utilities came to naught in the $70 \mathrm{~s}$ and $80 \mathrm{~s}$, but the world wide web, \\ the Internet, mobile access, and a plethora of access devices have now made information \\ utilities within reach. Google's business model, IT infrastructure, and innovation strategies \\ have created the capabilities needed for Google to become the world's first global \\ information utility. But, the difficulty of monetizing utility services and concerns about \\ privacy, which could bring government regulation, might stymie Google's growth plans.
}

DOI 10.1007/s12599-008-0011-6

\section{The Authors

Rex Chen
Prof. Kenneth L. Kraemer, PhD
Prakul Sharma
University of California, Irvine
Center for Research on Information
Technology and Organization (CRITO)
5251 California Ave., Ste. 250
Irvine, CA 92697
USA \\ kkraemer@uci.edu}

Authors are listed alphabetically to denote equal contribution.

Received: 2008-04-02

Accepted: 2008-09-18

Accepted after 2 revisions by Prof. Dr. König.

This article is also available in German in print and via http://www. wirtschaftsinformatik.de: Chen R, Kraemer KL, Sharma P (2008) Google: Das weltweit erste "Information Utility"? WIRTSCHAFTSINFORMATIK. doi: 10.1007/11576-008-0116-z.

\section{Introduction}

In the early 1970s, futurists at the Rand Corporation and Stanford University proposed the creation of information utilities - the provision of computing and information service by a utility in the form of a national network where any person desiring information could gain access - much like gas and electric utilities, but on a national scale (Sackmann and Nie 1970; Sackman and Boehm 1972). Not to be left out, the idea was also promoted by the Computer Usage Development Institute in Japan, the British Post Office in the UK, and Bell Canada and the Telecommunications Board in Canada (Press 1974).

The idea was so revolutionary at the time that at least one critic called for a moratorium on the development of information utilities until the year 2000 so that research could indicate what the social impacts might be (Press 1974). The fateful year 2000 came and went without mention of information utilities, but the year 2008 has raised the concept once again as Google appears positioned to become the first information utility in the world (Carr 2008a) and concern about the potential social implications is raised once again (Maurer 2007).

Today, however, Google is mainly known for its unparalleled search engine technology, running on an efficient very large scale distributed computer system. It has become so successful that the verb "to Google" has ingrained itself in the vernacular as a synonym for performing a web search. The key to Google's success has been its strategic and innovative use of IT. Its search engine enables people to search the web for useful information with Google Search, Google Maps, Google Earth, and other applications, but places advertising related to the user's search along side the results. By linking ads to a variety of search-based web applications, and continually improving the relevance of the searches and the ads, Google has been able to monetize its search capability, achieve financial success, and increase the number of users to the point where it is the dominant search player in both the U.S. and the world. This IT-based strategy has allowed Google to reach more than $\$ 16$ billion in annual revenue, a stock price over $\$ 600$ per share and a market capitalization of nearly $\$ 200$ billion.

Over the next decade, Google plans to extend its existing services to the wireless world, to develop new services, and to expand its computing infrastructure to support this growth. The new services, combined with its own and partners' complementary products, have the potential to make Google the world's first information utility and bring its ambitious goal of "organizing the world's information" a little bit closer in time.

The information utility was defined by its originators "as mass communications systems in which the consumer interacts directly with a central computer and its associated information files from a remote terminal at his home, office, or school in his natural environment - in a manner such that he received the information at his terminal almost immediately after requesting it." The information utility also includes contributing physical elements such as "television displays, communications lines, computers, data stores, and support facilities" (Sackman and Boehm 1972, p. 17).

At its heart, the concept involves an analogy with public utility systems. As discussed by Nicholas Carr (2008a) in The Big Switch, private electric systems built and operated by individual companies were replaced by public utility networks whose economies of scale enabled them to operate at a far lower cost and with greater 
effectiveness. Similarly today, private computing and information services could be provided better and cheaper over a common computing network rather than through the myriad computing shops that now exist in companies. Not only would companies, governments, and other organizations benefit from economies of scale, but so would individuals, as all customers would pay based only on the computing and information services they used from the utility.

The Internet is the global broadband grid network that information utilities can use to deliver services to their customers. Other components of an information utility are in operation today, although in piecemeal fashion. Large scale computing services that can be accessed over the Internet are offered by IBM, HP, Microsoft, Oracle, and Google. Network-based software services are offered to SMEs and even some large companies by vendors such as SAP (ERP), SalesForce.com (CRM), and Workday (HR and finance). Massive storage services are offered by EMC while thin clients are provided by companies such as HP.

Whereas such companies might have strong capabilities in one of these components, Google has amassed powerful capabilities in all of them, as required for an information utility. Google's server farms hold about one million computers. Its proprietary software coordinates all the servers to form computing clusters in each of the company's data centers strategically located around the world. Its software applications such as Google Apps, Google Maps, and Google Earth provide software as a service. Its Android operating system enables cell phones, PDAs, and thin clients as well as pocket PCs to access services on the Internet.

In short, Google is the one company poised to realize the information utility vision over the next decade. Its strategy and business model produce large revenues that enable it to take a long term view and develop the necessary features. Its myriad products and services, undergirded by a vast computing infrastructure, enable it to enlist business partners and to support growth of the entire business ecology. These achievements stem from Google's innovation model that emphasizes hiring highly talented people and giving them the freedom to excel while also incorporating outside innovation through acquisition. The follow- ing sections describe these features, how they contribute to Google's capabilities for an information utility, and how its future developments will further enable the vision. The paper concludes with an analysis of the obstacles it faces in doing so, and lessons for other firms.

\section{Google's business}

\subsection{Business strategy}

Google's strategy has been to capture revenue from online advertising shown along with web-based searches. Its advertising revenue accounted for $99 \%$ of its total revenue of $\$ 16.59$ billion in 2007 . Approximately $64 \%$ of Google's revenue is attributed to ads placed on its own products and services websites (Google Search, GMail, Google Earth), whereas the rest is derived from its partners (e. g., CNN.com, nytimes.com, techcrunch.com).

In order to remain a forefront technology leader and innovator, Google has aggressively acquired start-up companies whose products strengthen the range of complements offered by Google and provide increased distribution channels for its advertising business. These acquisitions reinforce its expertise in online and traditional advertising. Going forward, Google's strategy is to increase revenue by targeting additional customers in online advertising. Out of the total $\$ 298$ billion spent on advertising in the U.S. in 2007, only $\$ 21.4$ billion was spent online with about $\$ 8.8$ billion attributed to search advertising (Capps and Ives 2007). Google is also expanding its advertising business beyond online marketing to other media, including radio and print media (Hoover 2006). This will help Google to provide its customers a range of options for their advertising campaigns.

Additionally, Google is investing in large data centers that will support an information utility. It spent $\$ 5.48$ billion on infrastructure over the last two years for data centers, servers, and networking equipment. In 2008 it launched Google App Engine, which is a utility computing platform for developers. Over the next ten years, Google's strategy is to move to the provision of computing and information services for companies and consumers via its IT infrastructure.

\subsection{Core products and services}

Google's business consists of search-based online advertising, which is comprised of three major components: AdWords, AdSense and a long list of complements to the first two services. AdWords is Google's advertising product and AdSense is an ad serving program that delivers relevant ads to Google's partner websites. The role of the complements like Gmail or Google Earth is to draw users to Google websites where they can be exposed to advertising.

AdWords is the backbone of Google's advertising business. It allows advertisers to create ads, insert them to the AdWords program, and choose the search keywords that determine when the ads show up next to a Google search query result. AdWords allows the advertiser to display a variety of ad formats and to target the ads to specific languages and geographic locations.

AdSense is Google's ad serving program that delivers ads on partner websites by automatically crawling the content of their web pages and showing ads that are relevant to the audience and the site content. "AdSense for search" allows a website publisher to provide website search to his visitors and to earn money by displaying Google ads on the search result pages.

Google's business model involves monetizing the online advertising delivered to people who use the Internet everyday through Google Search or other services. Revenue from AdWords and AdSense are generated using two different pricing schemes: cost-per-click (CPC) and cost-per-thousand impressions (CPM). Under CPC, the advertisers pay Google each time a user clicks on the text-based ad that appears online. If the ad appeared on a partner website that is enrolled in the AdSense program, Google splits the revenue with that partner. The revenue that the partner website owner earns depends on a number of factors like the amount that an advertiser bids on that website, the website traffic, and the number of clicks. For every dollar that Google brings in through AdSense and other places that distribute its ads, it pays roughly 78.5 cents back to sites that display the ads (Tedeschi 2006).

Under CPM, advertisers pay Google based on the number of times their ads appear on Google's partner websites, as specified by the advertiser. The price paid is the same whether users click on the ad or not. The advertisers select the sites 
where they would like their ad to appear and set a bid that applies to all these sites. The ads are then ranked for display based on the advertiser's bid, competing with other CPM and CPC ads. As will be discussed later, CPM is one of the monetizing schemes that might be used for Google's information utility services for those users who would be willing to have advertising appear along side the applications they use.

\subsection{Complements to Google's core products}

Underpinning Google's advertising business is an array of complementary products and services, some of which are internal and others provided by business partners. Complements are products or services that are consumed together, and provide the benefit of expanding the customer base and/or revenue. Products like Google Apps, Gmail, and Google Earth are classified as complements to Google's core business of advertising. Because complementary products play a critical role in driving users to advertisements, Google has a strategic focus on expanding the availability of these complements to multiple industry sectors and reducing their cost to the users (Carr 2007). Its complements currently span multiple industry sectors, including advertising, entertainment, news, software programs, and financial transactions (Tab. 1).

These complements, most of which are free, have the potential to generate revenue through advertising, subscriptions, or pay-for-use. ${ }^{1}$ In the mid term, Google continues to rely on advertising as illustrated by its efforts to monetize YouTube. But its long term success as an information utility may require moving to additional schemes such as pay-for-use (like other utilities) because some users may not want to continually be bombarded by advertising.

Google's business partners are also important complements. Some use its platform in their own businesses such as Amazon who uses Google's search engine or IBM who incorporates Google Docs in their offerings to business clients. Other partners develop mash-ups, which are applications that combine Google functionality with content or capabilities of their own. An example of the latter is

\footnotetext{
Google currently charges for premium services such as Google Earth Pro and Google SketchUp Pro.
}

\begin{tabular}{|l|l|}
\hline Tab. 1 Key complements to Google's core products \\
\hline Google Earth & Satellite imagery of geographical locations \\
\hline Google Map & View driving maps and directions \\
\hline Google Mobile & Search for cellular devices \\
\hline Google Video/YouTube & Search for video clips and TV programs \\
\hline Google Apps & Web-based communication and collaboration tools \\
\hline Google SketchUp & 3-D model design tool \\
\hline Google Search Appliance & Enterprise search engine \\
\hline Google Desktop & File search tool in the local machine disk storage \\
\hline Google Checkout & Online electronic payment system \\
\hline Google Scholar & Specific search tool for academic research papers \\
\hline GTalk & Web-based instant messenger \\
\hline Gmail & Web-based email client \\
\hline Picasa & Photography organization and editing tool \\
\hline Blogger & Online site to publish and share blogging information \\
\hline Orkut & Online social network community \\
\hline OpenSocial & Set of interoperable API tools for web-based social networks \\
\hline $\begin{array}{l}\text { Source: Wikipedia, List of Google products, http://en.wikipedia.org/wiki/List_of_Google_products, } \\
\text { accessed on 2008-09-18. }\end{array}$ & \\
\hline
\end{tabular}

Housingmaps.com, which combines data from Craigslist (online classified housing ads) with Google Maps to create an application that allows users to see houses for sale plotted on a map of the local area (Iyer and Davenport 2008). These companies, which form part of Google's ecosystem, bring in revenue, help promote the brand, expand the customer base, and provide services useful to customers. They help Google to create a virtuous cycle with benefits for all. Thus, as Google puts its information utility infrastructure in place, these companies will be key complements that help to achieve network effects.

\section{Google's IT infrastructure}

Google's IT infrastructure is the keystone of the entire business ecology, tying everything together and making it work. The general IT model is to build powerful systems that combine the use of commodity hardware and intelligent software to optimize speed, cost, scalability, and reliability. A search query result using Google's search engine must provide a response time within one second for satisfactory usage, so it uses parallel processing across multiple machines. Instead of purchasing the latest computers, Google's IT department purchases commodity machines at a greatly discounted price. Overall price per performance is more important than individual peak performance, and this enables Google to achieve superior speed at a fraction of the cost of using fewer, but more expensive high-end servers. It also enables substantial scalability. If more processing power is required, the system simply increases resources from additional computing machines to serve more user queries. This scalability is achieved by its proprietary operating system built on Linux that allows new computer clusters to plug in, be recognized globally, and be available for use immediately (Iyer and Davenport 2008). Google addresses the fault-tolerance problem in software by implementing reliability and redundancy functionalities in its system architecture.

How then does this structure help tie the whole business ecology together? Google's proprietary IT infrastructure enables the company to exert control from end to end and to enhance its own and its partners products and services. For example, Google App Engine enables third party developers to deploy new applications fast and easy on the web. Just as Google engineers can create new applications and test them with thousands of users, third parties can also create new applications that incorporate part of Google's functionality, test them, launch them, host them on Google's infrastructure, and reach customers all over the world via the Internet. As noted by Iyer and Davenport (2008, p. 61), “This benefits both parties: Google gets its product widely adopted, and its partners can devote their energies 
to develop product functionality important to their customers."

\subsection{Software technology}

Google's web-based search engine depends on a scalable IT infrastructure with complex software components and architectural design that support web page crawling, indexing, searching, and managing distributed files. The non-stop "web crawler" collects documents from the web and then stores information in the searchable database index. When a user sends a search query to the Google web server, a metric to find desirable results is computed and displayed on the web browser as output.

The core search technology is PageRank, an algorithm that determines web page relevancy by calculating the ratio number of outgoing versus ingoing links to a web page, and assigns numerical weights for the indexed web pages (Langville and Meyer 2006). Calculating outgoing and ingoing links may seem trivial at first, but the technique becomes computationally intensive and difficult as Google needs to analyze billions of web pages on the Internet, perform continuous calculations, and assign ranking scores for all web pages collected. The mathematical formula in PageRank has been published by the Google co-founders (Brin and Page 1998; Page and Brin 1998).

Along with PageRank, Google has developed other important software tools necessary to create efficient, fast, and scalable software capabilities. To speed up processing large data sets across multiple machines, optimizations in data extraction utilities were developed (MapReduce). To store files, index file meta-data information, and retrieve data files quickly, a large-scale database repository system was developed (BigTable). To address the scalability issue, an efficient file system capable of maintaining terabytes of data across multiple storage locations was developed (Google File System). To create interactive, real-time web-based applications, Google uses a software design methodology called Asynchronous JavaScript (AJAX). It has been used in products such as GMail, Google Earth, and Google Finance, and is instrumental in helping business partners and software developers create "mashups" with Google.

Similar to its large scale search engine, Google's information utility will require petabyte storage, systems scalability, and high-performance computing. Hence, these software tools - MapReduce, BigTable, and Google File System along with AJAX implementations - provide the capabilities needed to serve as the core software infrastructure for its information utility.

\subsection{Hardware technology}

Google has more than 25 data centers where low cost commodity Intel x86based PCs function as servers. The data centers are located around the world for risk management and to ensure that significant processing power is available for fast search engine access (Markoff and Hansell 2006). Each data center contains thousands of identical server farms replicating the data and services to serve user queries in local regions. The servers in each center have identical configurations, which contributes to operating efficiency. Google's Linux operating system is the hub that supports its own and other's complementary services. This IT infrastructure is a powerful platform that enables Google to store data, process information, and host applications on a massive scale for utility services to consumers, SMEs, and larger firms as well.

\section{How Google innovates}

Innovation at Google has been internally focused on building an IT infrastructure that is robust and enables easy creation of new products and services. Going forward, the information utility will require more externally-oriented innovation focused on supporting external developers and customer applications. But how does Google foster the innovation that leads to new applications? This is an important question because most companies cannot expect to imitate its IT infrastructure, but they can imitate its innovation strategies. Google uses the following four strategies.

\subsection{Explicit focus on R\&D}

Google's extraordinary revenue enables it to have a luxury few firms can enjoy today - an R\&D lab that focuses on developing revolutionary hardware and software ideas along with complementary services. More than one-half of the company's employees are engineers and scientists, and there might be hundreds of projects in development at any given time. Many prototypes are made available on the lab's website for the interested public to download and try in the beta stage. By launching these beta products and services publicly to be tried out, Google can see which ones take off, get feedback, and incrementally improve them without having to scrap a product that might take off with further development.

\subsection{Acquisition of talented people}

Google is among the most active high-tech companies in hiring top engineering talent, including technology industry legends and young guru programmers. During the technology bust, Google seized the opportunity to hire bright technologists who focused on search technology (Vise and Malseed 2005). Although Google's revenue did not grow rapidly at first, its employee brainpower did grow fast. Many of the individuals hired by Google were visionary inventors or technical leaders for their former employer, and whose technology was relevant to Google. ${ }^{2}$ Working at Google is not only attractive to people in industry, but also to university professors who have opted out of academic careers to work for Google (Pittsburgh Business Times 2005).

To ensure the quality of its workers, Google's employment screening process has become one of the most rigorous among all technology companies. Applicants are asked complex technical questions from at least half a dozen interviewers, with a recruitment committee hearing everyone's feedback (Schmidt and Varian 2005). An entire interview process at Google can take several months. It is estimated that Google still has around 100 applicants for every professional job (Iyer and Davenport 2008).

\subsection{Innovation culture}

Google not only hires talented people, but provides them with an environment that encourages risk taking, creativity,

\footnotetext{
2 A high profile example was a former Microsoft Vice President and academia professor, Kai-Fu Lee who left Microsoft to work for Google. Lee played a pivotal role in developing and driving Microsoft's China strategy. Microsoft feared a leakage of critical confidential information and pursued a legal battle against Google for a one year non-compete agreement. The case was settled between Microsoft and Google with the court judge placing a temporary restraining order on the type of projects Lee could work on at Google.
} 
and team work. Unlike many corporate environments, Google's headquarters operates most like a graduate school with daily guest speakers, mentoring by senior engineers, projects by individuals or teams, and encouragement of an open mind and out-of-the-box thinking. Google has also adopted a very flat organizational structure to allow engineering ideas to be widely circulated.

To encourage innovation, Google implemented a $20 \%$ rule wherein engineers must spend $80 \%$ of their time at work on Google's core products, but have freedom to dedicate the remaining $20 \%$ of their work time to "pet projects". Such freedom has enabled the engineers at Google to develop products such as Google News, Google Finance, Orkut, and GTalk. Similarly, Google's cloud computing initiative, which seeks to train the next generation of computer scientists to work with large scale databases, emerged from a computer scientist's $20 \%$ rule project. The pilot involved developing a course supported by a large-scale computer cluster with storage, an open source version of Google's MapReduce software, and data to work with for computer science graduate students at the University of Washington. With the aid of IBM, the project is being extended to six elite computer science programs whose faculty will do the teaching and later to other universities as well (Baker 2007). The initiative will create a new generation of computer scientists able to develop and support the infrastructure and applications for information utilities.

According to Iyer and Davenport (2008, p. 67), an important part of Google's innovation culture is rigorous data-based evaluation of project ideas, progress and results. They say that "A key ingredient of innovation at the company is the extensive, aggressive use of data testing to support ideas." Google engineers use click stream data from its own or its partner's websites to test and support new ideas or product offerings. They conduct thousands of natural experiments everyday on the Internet, such as offering multiple versions of a page design, an ad, or a word choice. They also offer tools to customers such as Google Analytics which allows customers to understand the value of their advertising. They use email to circulate ideas for new products that any employee can comment on and rate the ideas, providing an in-house market test. Once launched in beta, products are again evaluated by

Tab. 2 Core and complementary services from acquisitions

\begin{tabular}{|c|c|c|c|}
\hline Company & Technology & Acquired & $\begin{array}{l}\text { Google services (Comple- } \\
\text { ments) }\end{array}$ \\
\hline \multicolumn{4}{|l|}{ Core Infrastructure } \\
\hline Applied Symantics & Online advertising & 2003 & AdSense, AdWatch \\
\hline Sprinks & Paid advertising & 2003 & AdSense, AdWords \\
\hline Akwan IT & Distributed data processing & 2005 & Google File System \\
\hline Android Inc. & Mobile phone software & 2005 & Google Android \\
\hline Xunlei & Network file sharing & 2007 & Google File System \\
\hline Adscape & Video game advertising & 2007 & (In development) \\
\hline DoubleClick & Online media advertising & 2007 & (In development) \\
\hline PeakStream & Parallel processing & 2007 & MapReduce \\
\hline \multicolumn{4}{|l|}{ Complementary services } \\
\hline Deja & Usenet search services & 2001 & Google Groups \\
\hline Kaltix & Personalized Internet search & 2003 & iGoogle \\
\hline Where 2 Technologies & Internet mapping & 2004 & Google Maps \\
\hline Keyhole & Satellite imagery & 2004 & Google Earth \\
\hline Zipdash & Mobile GPS traffic updates & 2004 & Google Ride Finder \\
\hline Urchin Software & Web analytics & 2005 & Google Analytics \\
\hline Android Inc & Mobile phone software & 2005 & Google Mobile/Google SMS \\
\hline DodgeBall & Mobile social networking & 2005 & Google Mobile \\
\hline Measure Map & Blogging analytics & 2006 & Google Analytics \\
\hline Upstartle & Writely online word processing & 2006 & Google Docs \\
\hline 2Web Technologies & Web spreadsheet & 2006 & Google Spreadsheet \\
\hline YouTube & Internet video & 2006 & (In development) \\
\hline ImageAmerica & High resolution aerial cameras & 2007 & Google Maps \\
\hline Tusli & Mobile social networking & 2007 & Google Blogger API \\
\hline Zingku & Mobile social networking & 2007 & Google Mobile \\
\hline GrandCentral & $\begin{array}{l}\text { Web-based voice services and } \\
\text { mobile phone integration }\end{array}$ & 2007 & (In development) \\
\hline Jaiku & $\begin{array}{l}\text { Web-based activity stream sharing } \\
\text { and mobile phone integration }\end{array}$ & 2007 & (In development) \\
\hline Postini & Communications security & 2007 & (In development) \\
\hline
\end{tabular}

internal and external users and the data is used by management teams to determine whether they can be improved, launched, or scraped.

\subsection{Acquisition of innovative companies}

Although much is made of Google's internal innovation, the new products and services that have captured significant user market share (though not revenue as yet) have been external acquisitions such as online video with YouTube and blogging with Blogger (Carr 2008a). Many of the purely internal innovations have not had the same traction, but part of Google's genius is to know how to incorporate other technologies into its core infrastructure.
Between 2001 and 2007, Google acquired over 40 start-up companies and leveraged their technology and engineering talent. These acquisitions have not only created complements that might be monetized through the information utility, but also have contributed to Google's core infrastructure. For example, AdSense and AdWords were both enhanced with technologies acquired in 2003 from Sprinks and Akwan IT (Tab. 2).

To summarize the previous sections, Google's business model has produced large revenue that has allowed the company to generate complementary products and partnerships and create a virtuous cycle that brings benefits to all participants. Google's business runs on a 
robust IT infrastructure that provides the speed needed for efficient search while enabling scalability and reliability at low cost. These achievements are the result of an innovation model that gives highly talented people considerable freedom in a culture that encourages team work, sharing of ideas and risk taking, but evaluates their ideas with real world data and holds them accountable for results. These features constitute the basis for Google to become an information utility over the next decade.

\section{Future directions}

Although Google has developed some capabilities for utility services, and cloud computing is one of its key strategic directions in the future, it continues to invest in search based advertising, including expansion to new media and mobile networks. The goal is not only to strengthen its core revenue stream, but to expand the number of users on its platform who may become customers for utility services over the next decade.

\subsection{Investment in cloud computing}

Google has been exploring the idea of cloud computing, which may be the one development that most shapes Google's future. Cloud computing is a new paradigm that is similar to the information utility concept. The idea is that all the user's applications and data are stored on servers called "clouds," and the user can access these independent of devices, software platforms, and location. Thus, there is no need for individuals to store data and applications on their local PCs or for corporations to host their own data centers (Greenberg 2008). As put by Nicholas Carr (2008a), what Google “...wants to eventually become is the computer that people use instead of their PC or their company's data center - the world's computer."

Carr also argues that Google already is a lead example of the information utility. Google is a central computing utility that supplies search-based computing services. The online web applications like Gmail and Google Docs are a further step towards centrally provided computing services. Many people already use these applications online. This is significant because it involves a shift from the desktop PC paradigm to the cloud computing paradigm where data and applications are centrally stored on Google's computing infrastructure and the user can access the information when needed (Carr 2008a).

Google is also well positioned to become such a utility (Greene 2007). It has a huge computing infrastructure in place and large advertising revenue with which to invest further. Google Android will integrate mobile devices as well as PCs or thin clients to that infrastructure. Further, a partnership with innovative companies like Apple would enable Google to develop hardware that relies on the Internet for input, storage, and output. Google is also partnering with various universities and technology companies like IBM to support research into cloud computing.

In the meantime, Google will likely continue to generate the majority of its revenue from the advertising model that is linked to its search engine. But all of the different services it is developing for consumers and businesses will provide new opportunities to display advertising, and new opportunities to collect information and personalize ads more precisely. The big question for the long term is whether it will have a robust subscription model that will induce users and companies to pay Google for processing, storage, and software services enabled by cloud computing.

\subsection{Investment in new media}

Google has expanded its advertising business to include mobile, radio, print, $\mathrm{TV}$, and video streaming in addition to online. A look at Google's 2007 acquisitions (Tab. 2) shows that it has focused recently on broadening its advertising channels and on complementary products that support its advertising business. To enhance its advertising expertise, Google has acquired companies like Adscape (video game advertising) and DoubleClick (online advertising). Google has also acquired some companies that will strengthen its expertise in mobile applications (e. g. DodgeBall, Zingku, Grand Central). These acquisitions are intended to make Google a one-stop-shop for all kinds of advertising campaigns.

In addition to bringing new advertising services to the market, Google is also expanding its existing operations to a global scale. The contribution of international sources to Google's revenue represented $52 \%$ of sales in the second quar- ter of 2008 (O'Carroll 2008). This trend is predicted to continue as Google expands its AdWords and AdSense services to the global market in order to maintain industry dominance and enhance its opportunity to be a "global" information utility.

\subsection{Investment in mobile networks and applications}

Mobile wireless networks are expected to be the next big market for advertising. Google's entry would not only reduce the cost of the mobile Internet, but also broaden the availability of the wireless network and the applications for mobile devices. Its open source Android operating system is a key initiative towards making mobile applications more platform independent and allowing mobile phone users to select the type of handset and applications that they like on any cellular network. Accordingly, Google is investing heavily to improve the technology for mobile search and targeted location-based advertising. CEO Eric Schmidt has predicted a wireless industry future comprised of free or very low-cost cellular devices, subsidized by advertising networks (Reuters 2006).

Google is also working with the hand set manufacturers to design their hardware to support Android and the wireless network. Android provides the software to support the use of its search-based advertising products in mobile applications and thus contributes towards Google's strategy of using mobile networks for advertising. Through its \$10 Million Developer Challenge, Google is encouraging third party developers to create applications that run on the Android platform.

\section{Emerging challenges}

Google is a young company that has yet to be tested by serious adversity. Whether it is able to achieve the vision of becoming an information utility is still unclear, as it faces problems of how to monetize its services beyond advertising, a growing concern about privacy and other social issues, and calls for government regulation.

\subsection{Monetizing services beyond advertising}

The advertising model has worked well for Google and it might use the model 
for utility services as well. It would allow users to access a wide range of utility applications online and stream advertising messages alongside the main application content much as it does now. The biggest advantage of this model is the free services for users. This might be the ideal solution for private users. However, businesses will have reservations because of the privacy and security concerns and the distractions that the advertisements might cause. Indeed, the biggest problem that Google may face is getting the big corporations, which form a major part of the potential market, to adopt these services. Since these corporations have already invested millions of dollars in customized solutions, convincing them to switch would be a hard task. Therefore, two other methods of monetizing utility services have been proposed: charging based on usage and providing hardware appliances that run these services (Rappa 2004; Diana 2008).

The first method is that of utilities like electricity or gas - charging based on usage (storage, processing or volume of transactions). It is the simplest way to monetize these services. Amazon already offers remote computing services over the Internet to software developers who want to create applications on a robust technology platform with multiple high end servers, but cannot afford that infrastructure. Another version of this model could be similar to the pre-paid cell phone services offered by most mobile carriers. Customers would not be bound by a fixed price or long term contracts, and would pay only for what they use. This flexibility has special value for SMEs. The advantage of this model, which offers some appeal to larger companies, is the personalized environment much like the normal desktop environment with few distractions from external sources like unwanted advertisements.

Another method is providing hardware appliances that will run these services with monthly or yearly subscriptions much like the cable television model being used today. Instead of different channels offered by the cable provider, the service provider will offer a menu of applications that the users can choose from. The advantage of this model for the consumers would be the availability of different service plans that they can use depending upon their needs. However, the disadvan- tage would be the payment of fixed rates independent of usage.

It is likely that Google will use a combination of these models for its utility services. The pay per usage model could be the initial choice for cost conscious users. The subscription model might be the choice of heavy users as they would pay a fixed fee for only the services they need. The advertising model can be integrated with both of the above models depending on user willingness to view ads. This would make the revenue from subscriptions and advertising a bonus, not a necessity. But none of this will be easy. Google bought YouTube for $\$ 1.65$ billion in 2006, and has yet to find the monetization breakthrough that will enable it to roll out a widespread advertising platform without annoying users of the site (Richards 2008).

\subsection{Privacy and other social issues}

The "googlization of everything" is raising social concerns in the U.S. (Carr 2008b) and elsewhere. Maurer's (Maurer 2007) report for the Austrian government on the Danger of Large Search Engines describes a number of concerns including: the copy-and-paste syndrome of extracting online text and transforming it to other forms; plagiarism; intellectual property violations; and the stultifying presumption that "if Google doesn't find it, it doesn't exist" with the consequence that Google defines knowledge in a way no single source of information has been able to do in the past. Some of these issues are slowly being resolved by new services such as Plagiarism.com, which provides the capability to have a student paper reviewed for possible plagiarism. Intellectual property violations are increasingly being worked out in precedent-setting court cases. Others may be cultural issues requiring the development of social rules and norms. Nonetheless, all are serious issues requiring attention as the Internet amasses more information and search engines greatly increase the visibility of information for billions of users.

We focus here on privacy threats, many of which are endemic to the Internet but exacerbated by Google's growing search capabilities and global scope. When one enters a search query on the Google site, information such as search keyword, IP address location, and user cookie details are collected by the Google server machines. Google claims that these statis- tics are only used by their search engines to better gauge user preferences, hence providing better search results. However, this is a significant invasion of user privacy as it allows Google to gain deep knowledge on its users, with insights on topic interests, intents, and lifestyles. And there are privacy issues with respect to Google Health and Google's work with hospitals to make medical information more searchable across platforms for doctors, hospitals, and patients.

Google claims in its privacy policy that it has no intention to release user search patterns or commercialize the data to third party companies. However, Google is a publicly traded company that needs to serve the interests of its shareholders with the goal of generating revenue and achieving profitability. Due to intense regulatory scrutiny and privacy advocacy, Google changed its search privacy policy in 2007 to only collect and keep log files of search queries and cookies on its servers for up to two years, after which the information is deleted from Google's IT infrastructure.

In an effort to create a geographical web enabling users to browse points of interest around the world, Google Earth has made satellite imagery and aerial photography available to view online. However, this has triggered privacy concerns among governments because the images show military bases and specific landmark building locations which can be used by terrorists or other enemies. Although the images are available through various private companies, the governments of the U.S., UK, South Korea, India, and Russia view their global availability through Google as a threat to national security and Google has therefore blurred the images or blocked them entirely.

Google's expansion of the Google Maps service to include Street View, raises other privacy issues. The Street View project was launched in 2007 as an experimental project that mounted cameras on taxi cab rooftops to take panoramic street views of several U.S. metropolitan cities. This has brought outcries from consumers about personal privacy as Google Maps Street View shows pictures of people, homes, and the nearby surroundings without permission. Several lawsuits on trespassing are in court.

As Google continues to make more types of information (text, pictures, videos) universally accessible for search, it will need to address how and why Google 


\section{Abstract \\ Rex Chen, Kenneth L. Kraemer, Prakul Sharma \\ Google: The World's First Information Utility?}

In only ten years, Google has achieved remarkable success from online searchbased advertising. Its search engine is dominant, and its IT infrastructure is the most powerful computing system in the world running on over one million computers and serving more than one billion users globally. Google makes money by using its search engine to deliver online advertising alongside responses to user searches for information, goods, maps, directions, and a host of other services. Its capabilities make it likely to become the world's first information utility - a concept similar to electric utilities that provide services to many corporations and individuals alike. Constant innovation is the key to Google's success and offers lessons for other companies: hire talented people, have them work in small teams, and give them freedom to excel, but use a rigorous data-based approach to evaluating results and making course adjustments.

Keywords: Google, Information utility, Business model, Search engine, Webbased advertising, IT infrastructure, Scalability can and should be the trusted authority. While Google's motto “don't be evil” may work well within the company, not everyone else in the world subscribes to that motto and Google may need to be more proactive where privacy is concerned. Utility services will only add to these issues as they will not only increase the amount of personal information available, but if successful with larger companies, they will greatly increase the amount of internal corporate information in Google's network. Until it finds ways to demonstrate that its systems are not only fault tolerant, but are secure and non-competitive, it will have difficulty attracting large companies and government agencies to the utility services.

\subsection{Calls for regulation}

The early advocates recognized that information utilities would have significant economic and social ramifications and therefore should have explicit social objectives (equal access and privacy protection) and be regulated by governments to ensure competition (Sackman and Boehm 1972). Maurer's study (Maurer 2007) and claims of unfair competition by rivals such as Microsoft are resulting in calls for government regulation of Google. So far, the U.S. has resisted being drawn into regulation based on "potential" social harms. And in regulatory court, Google has been on the winning side of competition challenges. For example, regarding the GoogleDoubleClick merger, both the European Commission and the U.S. Trade Commission said the merger would not hurt competition because the two firms occupy different parts of the market, and advertisers would be able to opt for alternatives, including services from Microsoft, Yahoo, and AOL (Story and Shannon 2007; Castle and Helft 2008). However, the growing chorus of people critiquing the social ramifications of Google is likely to bring action around privacy concerns in the U.S. Congress and the European Union. Although Google has generally responded to specific, actionable concerns by change to its practices, some critics feel it should be more proactive. Still, having the goal of "organizing the world's information" is not the same as the claim that Google is "dominating the world." Microsoft, Yahoo, IBM, Baidu, Amazon and others are working hard to ensure that Google is not the only search engine or the only information utility.

\section{Conclusion}

\subsection{Lessons for other firms}

Google is unique in ways that limit the lessons for other firms. For example, Google faces far less risk in new product development than the usual firm because it can introduce half-finished products online, and it knows that even if they fail to gain a big market share, they will still produce returns from advertising revenue and provide valuable data on customer behavior. Nevertheless, Google's innovation model can be imitated. In simple terms, the model involves hiring highly talented people for new product development, focusing $R \& D$ on products while explicitly allowing time for independent research, creating many small teams with considerable freedom, and using a data-analytic approach to evaluating ideas, progress and results. While most companies are limited in the resources they can devote to innovation, they can take the same approach, especially the use of data and testing, to evaluate innovative ideas.

The coming information utility means that many companies will likely shift more of their information services from in-house data centers to the web over the next decade because it will be convenient and less costly. This is already happening with individuals and SMEs. Even individuals in large enterprises are using GMail for business purposes because it enables them to access their email, data, and applications anytime, anywhere without being tied to corporate systems. Large companies, which have big investments in complex in-house systems, will probably be the last to switch, but many are very likely to do so when the economic benefits are compelling. As companies make the shift, there will be more time for staff to mine the massive amounts of data within the company and outside in order to better understand its customers and markets, thereby discovering new business opportunities.

Although Google is not making money from web applications outside of its searchbased engine, other companies are doing so. Salesforce.com supplies CRM applications and ADP provides payroll processing; both are successful, growing busi- 
nesses and point to the viability of offering services via the Internet. More importantly, they show that there are opportunities for other companies who can become part of the utility's business ecology as suppliers of additional services through the utility (e. g., Housingmaps.com) or as a supplier of hardware such as mass storage and "thin clients" for users. Although a computing utility might be the major hub in the network, other firms will find opportunities for new business as suppliers to, or partners with, the information utility. Finally, Google will not be the only utility. Although Google might be the first to be global in scope, there will be other utilities, both country-based and multinational.

\subsection{Concluding comment}

In only ten years, Google has gone from an Internet start-up to the dominant player in web advertising based on search technology. The use of IT has been strategic to Google's success with its search technology, core products like AdWords and AdSense, and its complements such as Google Apps, GMail, Google Maps, and Google Earth. Although Google continues to expand search-based advertising, it is using its massive IT infrastructure to launch information utility services to individuals, SMEs, and even larger firms.

However, there are challenges ahead. Will someone come up with a better search engine? Microsoft is certainly trying (Ferguson 2005) and Google alums have launched a start-up company which they claim "reinvents" search (Guynn 2008). Will Google be able to lead in international markets where there might be a national champion (e. g. Baidu in China) or where information dissemination is highly regulated? Will Google be able to monetize its services beyond ad revenue? Will the massive amounts of information collected on a daily basis result in privacy invasions that bring government regulation and stymie its growth? And will Google be able to dominate utility services as it has search services when the competition gets even more intense from industry giants such as Cisco, IBM, AT\&T, and Microsoft who have their own plans for information utilities?

\section{Acknowledgements}

This research has been supported by grants to The Personal Computing Industry Center (online at http://pcic.merage.uci. edu) from the Alfred P. Sloan Foundation and the U.S. National Science Foundation. Any opinions, findings, and conclusions or recommendations expressed in this material are those of the author(s) and do not necessarily reflect the views of the sponsors.

\section{References}

Baker S (2007) Google and the wisdom of clouds. Business Week. http://www.businessweek. com/magazine/content/07_52/ b4064048925836.htm. Accessed 2008-01-20

Brin S, Page L (1998) The anatomy of a large-scale hypertextual web search engine. Computer Networks 30(1-7):107-117

Capps B, Ives N (2007) US ad spending growth slows way down. Advertising Age. http://adage.com/mediaworks/article?article_id=118852. Accessed 2008-01-20

Carr N (2007) The Google enigma. Strategy and Business. http://www.strategy-business.com/ media/file/sb49_07404.pdf. Accessed 2007-0408

Carr N (2008a) The big switch: our new digital destiny. Norton \& Company, New York

Carr N (2008b) Is Google making us stoopid? The Atlantic 302(1):56-63

Castle S, Helft M (2008) Europe backs Google bid to acquire doubleclick. http://www.nytimes. com/2008/03/12/technology/12google.html. Accessed 2008-04-08

Diana R (2008) Utility computing: a business model for the twitter economy? http://mashable. com/2008/07/06/utility-computing/. Accessed 2008-07-10

Ferguson CH (2005) What's next for Google. http://www.technologyreview.com/ articles/05/01/issue/ferguson0105.asp? $\mathrm{p}=5$. Accessed 2007-02-20

Greene K (2007) Google's cloud looms large. Technology Review. http://www. technologyreview.com/Biztech/19785/page1/. Accessed 2008-04-08

Greenberg A (2008) When Google grows up. http://www.forbes.com/2008/01/11/googlecarr-computing-tech-enter-cx_ag_ 0111computing.html. Accessed 2008-04-08

Guynn J (2008) Google alums rev up a new search engine, dubbed cuil. http://www.latimes.com/ business/la-fi-search28-2008jul28,0,6621332. story. Accessed 2008-07-28

Hoover JN (2006) Google secrets. http://www. serverpipeline.com/showArticle.jhtml?articleld $=177105859$. Accessed 2007-07-28

lyer B, Davenport TH (2008) Reverse engineering Google's innovation machine. Harvard Business Review 86(4):58-68

Langville AN, Meyer CD (2006) Google's page-
Rank and beyond: the science of search engine rankings. Princeton University Press, New Jersey

Maurer H (2007) Report on dangers and opportunities posed by large search engines, particularly Google. Institute for Information Systems and Computer Media, Graz University of Technology, Graz

Markoff J, Hansell S (2006) Hiding in plain sight, Google seeks more power. The New York Times. http://www.nytimes.com/2006/06/14/ technology/14search.html?pagewanted=1. Accessed 2007-07-28

O'Carroll T (2008) Google's international revenue outstrips US for first time. Media Week. http:// www.brandrepublic.com/MediaWeek/ News/832812/Googles-international-revenueoutstrips-US-first-time/. Accessed 2008-07-28

Page L, Brin S (1998) Pagerank, an eigenvector based ranking approach for hypertext. $21^{\text {st }} \mathrm{An}$ nual ACM/SIGIR International Conference on Research and Development in Information Retrieval. Melbourne

Pittsburgh Business Times (2005) CMU professor to head Google-pittsburgh center. http://www. bizjournals.com/pittsburgh/ stories/2005/12/12/daily35.html. Accessed 2007-01-15

Press LI (1974) Arguments for a moratorium on the construction of a community information utility. Communications of the ACM 17(12):674678

Rappa MA (2004) The utility business model and the future of computing services. IBM Systems Journal 13(1):32-42

Reuters (2006) Google CEO sees free cell phone service. http://www.msnbc.msn.com/ id/15700344/. Accessed 2008-07-11

Richards J (2008) Google to roll out new video adverts on YouTube. http://technology. timesonline.co.uk/tol/news/tech_and_web/ article3901796.ece. Accessed 2008-01-20

Sackman H, Boehm BW (1972) Planning community information utilities. AFIPS Press, Montvale

Sackmann H, Nie N (1970) The information utility and social choice. AFIPS Press, Montvale

Schmidt E, Varian H (2005) Google: ten golden rules. http://www.msnbc.msn.com/ id/10296177/site/newsweek/print/1/ displaymode/1098/. Accessed 2008-01-15

Story L, Shannon V (2007) Doubleclick and Google get a clearance to merge. The New York Times. http://www.iht.com/ articles/2007/12/21/business/google.php. Accessed 2008-04-08

Tedeschi B (2006) Google's shadow payroll is not such a secret anymore. The New York Times. http://www.nytimes.com/2006/01/16/ technology/16ecom.html?_r=1\&oref=slogin. Accessed 2007-02-15

Vise DA, Malseed M (2005) The Google story. Delacorte, New York 